\title{
LA CORRESPONDENCIA DE UN SOLDADO ESPAÑOL DE LAS GUERRAS EN HUNGRÍA A MEDIADOS DEL SIGLO XVI. COMENTARIOS AL DIARIO DE BERNARDO DE ALDANA (1548-1552)*
}

\author{
In memoriam Ferenc Szakály
}

por

\section{ZOLTÁN KORPÁS}

Universidad Eötvös Loránd

Depto. de la Historia Húngara

RESUMEN: El objetivo de este artículo es doble. Por una parte completar los conocimientos de la vida y actividad del maestre de campo, Bernardo de Aldana. Por otra, poniendo dicha personalidad y su actividad en un contexto bistorico, demostrar que la presencia de un tercio español en Hungría no era un caso aislado, sino formaba paste de una política militar consciente de Carlos V que con cierta periodicidad fortalería con tercios viejos las posicioner de Fernando I en Hungria. En un nivel más amplio quisiera llamar la atención al becho que el largo conflicto entre los Habsburgos y la Sublime Puerta de Constantinopla no puede ser bien entendido si sólo lo analizamos de una visión nacional-regional, sin tomar en cuenta las relaciones supranacionales de aquellas luchar antiturcas de las dos regiones distantes, Hungria y España.

Palabras Clave: Bernardo de Aldana. Tercios viejos. Luchas antiturcas. Hungría. España. Historia militar. Siglo XVI.

\footnotetext{
* Quisiera expresar mi especial agradecimiento por la ayuda y sugerencias que me han prestado mis tutores en España, Dr. D. Enrique Villalba Pérez, vicedecano de la Licenciatura en Humanidades de la Universidad Carlos IIl en Madrid, y Dr. D. David García Hernán, profesor en la misma Universidad. Esta versión es la traducción del estudio preliminar de la publicación de la correspondencia en español y latín de Aldana que aparece paralelamente en artículos consecutivos de la publicación periódica Fons, Budapest, Hungría.
}

Hippania, LX/3, nim. 206 (2000) 881-910 
ABSTRACT: The purpose of this study is double. Firstly, it aims to complete our knowledge about the life and activity of the Spanish mercenary Bernardo de Aldana (1548-1552). Secondly, it will place bis personality and activity in a historical context, demonstrating that the presence of a Spanish regiment in Hungary was not an isolated case. It was part of the military policy of Charles $V$, wbo frequently sent Spanish troops in order to strengthen the pasition of bis brotber Ferdinand. The struggle between the Hapsburg and Otsoman empires cannot be understood on a national or regional level without taking into account the international context: the antiTurkish campaigns of two distant areas, Spain and Hungary.

KEY wORDS: Bernardo de Aldana. Tercios viejos. Wars against Turkey. Hungary. Spain. Military history. Sixteenth Century.

En la Biblioteca del Real Monasterio del Escorial se halla el manuscrito de la Expedición de maestre de campo Bernardo Villela de Aldana'. Fue publicado -en edición incompleta - en su lengua original, en español en $1878^{2}$. Existe una edición - también incompleta - en polaco ${ }^{3}$. En 1986 apareció la primera publicación completa y crítica de este manuscrito ${ }^{4}$. La labor fue hecha por el traductor László Scholzs y por el historiador trágicamente fallecido en julio de 1999, Ferenc Szakály.

De la vida de Aldana tenemos pocas informaciones. Era un artillero famoso y conocido. En 1539 había ocupado el cargo de capitán de infantería en Italia. En la guerra contra la liga de Esmalkalda en 1546-47 servía como capitán de caballería en el ejército de Catlos $\mathrm{V}$ y defendió con bravura el puente de Torgau, conque facilitó el triunfo del emperador en la batalla de Mühlberg. Los comienzos de 1548 el César lo promovió como maestre de campo del tercio de Nápoles y luego le entregó las 7 banderas de 1400 soldados, con los que entró en Hungría hacia los finales de 1548 , ya como oficial subordinado al hermano menor del Emperador, al rey Fernando ${ }^{6}$. El tercio español y su maestre de

\footnotetext{
I La signatura del códice: V. II. 3, pp.177-234.

${ }^{2}$ RODRIGUEZ Villa: Expedición del mastre de campo Bernardo de Aldana á Hungria en 1548. Madrid , 1878. La relación de Juan Villela de Aldana fechada de Transilvania: PASCuAL GaYANGos: Memorial Histórico Español. Madrid, 1875, X. 487-528. Gabruel. Fernández DuRo: Tres artilleros ilustres. In: Memorial de artilleria. 10 (1824) 270-273.

${ }^{3}$ X. FeLIKS ROZANSKI: Wyprawa na Wegry Bermarda Aldany. Krakowie, 1882.

4 FERENC SZAKAIY: Bernardo de Aldana magyarországi hadjárata (1548-1552). Európa Könyvkiadó, Budapest, 1986. Trad.: LÁszió ScHOLZ.

s En este momento Jefe del Departamento de la filología española de la Facultad de Filosofia y Letras de la Universidad Eötrös Loránd en Budapest.

${ }^{6}$ No sabemos exactamente la fecha del nombramiento de Aldana, pero disponemos de una carta de Carlos V, fechada de 11 de febrero de 1548 en Augsburgo en que otorga la merced de la tenencia de Sedella de 100.000 maravedies de valor al capitán Bernardo Villela de Aldana. In: Arcbivo General de Simancas (AGS), Contaduría de Sueldos, $2^{4}$ serie. Leg. 376, Sedella. Según el testimonio del
} 
campo participaban en el país magyar en varias expediciones. (En la organizada contra los oligarcas del norte de Hungría en 1549 , en la construcción y defensa de castillo de Szolnok (Hungría) ${ }^{7}$ en 1550 y en la guerra contra los turcos en 1551-52.) El 28 de julio de 1552, abandonó el castillo de Lippa (Lipova, Rumanía) y la corte real incoó un pleito contra él, lo que acabó con la pena de muerte de Aldana y con la confiscación de sus bienes. Pero la pena de muerte jamás se cumpliría. Fue excarcelado — como fruto de la intervención, en nombre de Felipe II, de Luis Venegas Figueroa y Pedro de Lazo de Castilla - de Trencsén (Trenčin, Eslovaquía) en $1556^{8}$. Al haber salido de Hungría, por el mandamiento de Carlos I fue designado como general de artillería en Lombardia y Piamonte9. Más tarde, en 1559 como general de artillería en Nápoles ${ }^{10}$.

diatio (SzAKály, 1986. 22-26) Aldana llegó a Hungría durante la dieta de Posonio que duraba de 28 de octubre de 1548 hasta los finales de febrero de 1549 ya como maestre de campo.

1 Como los acontecimientos mencionados en este artículo ocurrían en rerritorios que en aquel entonces pertenecian al Reino de Hungría, indico el nombre húngaro y en parentesis el nombre actual y el Estado a que pertenece. En caso de lugares pertenecientes al actual tetritorio de la República de Hungría solo indico el país.

* Real Academia de la Historia Colección de Salazar y Castro A-52. fo. Carta de Felipe II a Fernando, Hampton Court, 18 de julio de 1555. (En el catálogo de la colección figura erróneamente: carta de Fernando a Felipe II, de Augsburgo.)

uquanto bolgara (a Felipe II) que Vuestra Majestad mandase dar libertad al maestre de campo Bernardino de Aldaña... y parecerme que con baver estado en prisión tres años babia purgado vastamente la culpa si alguna tubo....

La respuesta de Fernando no tardaba mucho: Salazar y Castro, A-52,fo. 11 y 11 v. 7 de enero de 1556, Viena. Fernando a Felipe II.

"Por una carta que al licenciado Gamiz mande escrivir desde Posonio (Pozsony, hoy Bratislava, capital de Eslovaquia) y por las que babia escrito Leis Venegas y dicho despues de su boca a Vuestra Alteza babia entendido la libertad del maestre de campo Bermardo de Aldana llevador desta y las bonestos y buenos reppectos por los quales se dirijio hasta la celebración de la dieta de Hangria que en aquella ciudad suve... y baviendo de ir el dicho mastre de campo a presentarse a Vuestra Alteza y besarle las manos como debe por el favor $y$ merced que para esta su livertad le ba becho Vuestra Alteza le baga o carga de los de su profesion en que Vuestra Aliteza lo mande emplear...*

9 Relación de las cartas de duque de Alba 18 de octubre de 1555, AGS. Estado, Milán, leg. 1208, P9.:

*...Que a Cesaro de Napoles encomendo el cargo del artilleria que esta vaco por fallecimiento de don Ramon de Cardona y no ballando para el persona mas conveniente que la del maestre de campo Aldana, supplica se scrivia a los neyes de Romanos y Bobemia que le den libertad.....

Es posible que esa opinión del duque había originado la intervención diplomácica de Felipe II y de su hermana, Maria, reina de Bohemia, que traería la libertad a Aldana.

10 sPor una relacion que me ba enbiado el maestre de campo Aldana que be escrito particularmente de

la manera que estan las sierras maritimas y otras de la frontera desse reyno (de Nápoles- ZK) por lo que entendemos que importa a su seguridad y defension, poner en ellas tado buen recaudo y con brevedad tanto mass agora con la nueva que se tiene que franceses ban pedido el armada al turco para que venga este verano.... Escribió Felipe II a Cardenal de la Cueva el 26 de febrero de 1559. La relación minuciosa de Aldana y la correspondencia respectiva a ella se halla en el AGS, Estado, Nápoles, leg. 1049, p 91-97, 131 
Murió como preso herido en una galera turca, luchando en la batalla naval de mayo del 1560 en Djerba contra los mismos enemigos contra quienes había luchado en Hungría ${ }^{11}$.

La publicación magyar completa una laguna de estos años tan cruciales de la historia de Hungría. El imperio surgido a causa de las herencias de emperador Carlos $\mathrm{V}$ por su extensión y heterogeneidad llegó a confrontarse por lo menos con tres mayores centros, oponentes a la hegemonía de los Habsburgo: La Francia de los Valois, la oposición política de los príncipes alemanes, escondido detrás del protestantismo y la expansión del Imperio Ottomano. Este último - junto con otras influencias- forjaba la ideología europea, enlazada a la Edad Media y renovada por Catlos V: La Universitas Christiana. A causa de la descomposición política, económica y social de Europa esa idea favorizada por el César no podía prevalerse sobre la realidad política, dejando la exigencia de la Cruzada contra los turcos en nivel de intereses mucho más inferior. Pero el avance turco por el Mediterraneo Occidental y por los Balcanes hacia Europa Central Oriental en la primeras décadas del siglo XVI acercaban los intereses de regiones tan distantes como la Peninsula Ibérica y el Reino de Hungría. ${ }^{12}$ Desde punto de vista de la Puerta Sublime el Mediterráneo y Europa Central Oriental eran los terrenos optimos de donde se podría encercar los territorios del enemigo más potente, el mundo cristiano encabezado por el emperador y el papa. Como un ejemplo de esta mentalidad estratégica, que me atrevo a llamar bifrontismo, se manifiesta en la ocupación turca de la ciudad Otranto entre 1480-81, cuando después de varias décadas de expansión turca por los Balcanes el ejército turco inesperadamente cruzó el Adriático y estableció una cabeza de puente a «un tiro de arcabuz» del centro ideológico de Europa, de Roma. El temor de poder ser inquietado y atacado por los turcos por una frente continental y marítima, de varios mil kilometros de longitud preocupaba la política mundial de Carlos $\mathrm{V}$, afectado por sus dominios dispersos y continuamente atacados por la fuerza otomana.

\footnotetext{
(la relación: $\mathrm{f}^{\circ}$ 95, de 1 de enero de 1559.) Corno merced real por el servicio hecho, hacia los finales de agosto, comienzos de septiembre, Aldana fue nombrado capitán general de actillería de Nápoles:

«S. C. R. Magestad. Venido que fue el duque de Alcala le informe de todas las fortificaciones y fabricas deste reyno como Vuestra Majestad me mando por su carta y se lo di por memoria, a la mesma sazon llego el titulo de mi cargo de la artilleria deste reyno y presentelo al virrey...." (Aldana a Felipe 1I, 18 de septiembre de 1559, Nápoles. AGS, Estado, Nápoles, leg. 1049, $f$ 149, 150.)

"La relación de PEDRo BaRRANTES De MALDONADO sobre la empresa de Djerba en Colección de libros españoles raros o curiosos. Tres relaciones bistóricos. Madrid, 1889. t. XIX. 207-209. Véase cambién los documentos de AGS, Estado, Nápoles, leg. 1050, fo80. Carta de la viuda de Aldana, Beatriz de Tovar a Felipe II a 25 de junio de $1560 ; \mathrm{P}^{\circ} 127$. Carta del reniente de Aldana, Juan de Bolanos a Felipe II, a 7 de septiembre de 1560. AGS, Esrado, Sicilia, leg. 1125, f 52 . Hernando Zapata al virrey de Nápoles. Messina, a 19 de mayo de 1560; f59. Relación sobre la batalla de Djerba a 28 de mayo de $1560 ; f^{\circ} 106$. Lista de bajas hecha a 20 de agosto de 1560.

12 ZOLTÁN KORPís: Spanyol védelmi rendszer Észak-Afrikában V. Károly uralkodása alatt. In: Africana Hungarica (1998) 1. 53-74.
} 
Por estas razones, superficialmente expuestas el César no podía dejar sin respuesta la expansión turca en el Magreb, que ponía en peligro a los intereses españoles en sur de Italia y en Norte de Africa, e incluso amenazaba la orden interna de España, recién unida. Por el mismo motivo tampoco podía permitir el lujo de no apoyar a su hermano, Fernando en su lucha contra los turcos en Europa Central Oriental, cuando la caída de Hungría en manos de la Sublime Puerta hubiera significado el libre paso hacia el corazón del «Imperio Cristiano», hacia el Sacro Imperio Alemán. Tanto en las luchas y las finanzas del flanco mediterráneo, como centroeuropeo, España, sobre todo Castilla, ocupaba una posición primordial en los planes antiturcos de Carlos $\mathrm{I}^{13}$.

Hungría en las primeras décadas del siglo XVI vivía los años más tristes, tal vez paralelamente más heroicas de su historia hasta aquel entonces. El país, sumergido en luchas internas y crisis económica fácilmente sería derrotado por el sultán Solimán, el Magnífico. El 29 de agosto en la batalla de Mohács no sólo murió el rey húngaro y checo, Luis II de la dinastia de los Jagellones y junto con él la flor y nata de la élite política del país, sino el desastre llevó consigo la descomposición de la tierra magyar. La corona de San Esteban discutida por dos pretendientes: por una parte el hermano menor de Carlos V, Fernando I, casado con la hermana del difundo rey, Ana de Jagellones ${ }^{14}$; por otra parte János (Juan) Szapolyai (Zapolya en otras fuentes), voivoda de Transilvania ${ }^{15}$. El tercer protagonista, el sultán de los turcos, Solimán el Magnífico, aprovechaba las décadas de guerras internas y civiles entre los dos bandos cristianos para atacar el Sacro Imperio Romano, ampliando sus conquistas en Hungría y avanzando hacia Viena ${ }^{16}$. Paralelamente los turcos lograban establecer su domina-

${ }^{13}$ Sólo indico aquí unas monografias imprescindibles para el estudio del reinado de Carlos V, sin la exigencia a totalidad. BRANDI, KARL: Carlos $V$. Vida y fortuna de una personalidad y de un imperio mundial. México, 1993, CHADOB, F.: Carlos V y su imperio. Madrid, 1992, FerNÁndez Álvarez, MANUEL: Poltica mundial de Carlos I y Felipe II. Madrid 1966, Úlcimamente ha publicado una monografia excelente, donde ha tratado también la situcaión de Hungría: Carlos $V$, el Cérar y el Hombre. Espasa-Calpe, 1999. LYNCH, J.: España bajo los Austrias. Imperio y absolutismo (1516-1598). Madrid, 1987, BeleNGuer, E.: Del oro al oropel. La begemonia bispánica en Europa. Barcelona, 1997. Jover ZAMORA, José MAŔA : Carlos Vy los españoles. Madrid, 1963.

If El tratado de matrimonio hecho en 1515 ofrecía un pacto muruo entre las dinastias de los Habsburgo y Jagellones. Ana de Jagellones se casó con Fernando de Austria, mientras Luís con la hermana de Fernando y Carlos, con María de Hungtía, gatantizando de esta manera - en el caso de la muerte del rey húngaro y checo, sin heredero legítimo - el acceso a ambos tronos.

13 La pretensión de Szapolyai se basaba en las decisiones de las cortes de Hungria, hechas en Rákos, donde los estamentos declararon en 1505, que los húngatos jamás cederían el trono a un extranjero si no corriera en sus venas la sangre de los «escitas", o sea de los húngaros.

16 Intento a resumir brevemente las etapas más destacadas de la expansión turca hasta 1541. Como ya se ha mencinado, los turcos derrotaron a Reino de Hungría en 1526, en Mohács. Hasta 1541 la Puerta Sublime intentaba a dividir al pais, sin la directa ocupación, apoyando el pretendienre «nacional» contra el Habsburgo, manteniendo así la descomposición del reino, que le facilitaba la intervención y la ocupación militar en cualquier momento. Cuando el status quo establecido por los turcos se desequilibraba al favor de Fernando, gracias a la ayuda constante de los reinos de Carlos V, 
ción y administración en Argel y en otras ciudades del litoral magrebí, amenazando la estabilidad política, militar y económica de España y los intereses en Norte de África y las relaciones marítimas en el Mediterráneo Occidental.

Así las dos regiones lejanas - España y Hungría - estaban en conexión tanto por los intereses dinásticos como por la razón política y geoestratégica del desafio turco. Esto lo demuestra la correspondencia activa de Carlos V con su hermano Fernando, rey de Hungría y de Bohemia desde $1526^{17}$. Leyendo estas fuentes podemos sacar la conclusión que el emperador - a causa del avance turco por el Mediterráneo, por Europa Central Oriental- tenía que prestar atención, invertir dinero y fuerza militar en el apoyo de su hermano económicamente mucho más limitado. Mientras el otro pretiendente, Szapolyai forzadamente aceptaba la ayuda no gratuita del turco.

Esta perspectiva nos permite entender porque pasaban entre 1526 y 1556 miles de soldados de los tercios españoles por Hungría: o en lucha contra el pretendiente nacional, o en contra los turcos ${ }^{18}$.

Desde 1541 el conflicto entre los dos bandos cristianos sufría grandes cambios. La paz secreta de Várad (Oradea, Rumanía) ${ }^{19}$ de 1538, que prometía la

entre ellos a España, la Puerca siempre intervenía, como ocurrió en 1529 , y 1532 con los ataques contra Viena, restituyendo así el status quo ante. Desde 1532 la política habsburga y unacional» se modificaba, reconociendo la necesidad de un acuerdo anciturco entre los dos, que con la unificación de las fuerzas cristianas en la región podrían proporcionar la expulsión de los turcos. Estas negociaciones desembocaton en 1538 en la paz secreta de Várad (Oradea, Rumanía) entre Fernando y Szapolyai, que fue ratificada por Carlos I en Toledo. Pero ninguno de los dos pretendientes quería guardar lo prometido e incluso Szapolyai en 1540 murí. Las negociaciones fracasadas de 1538 renían una consecuencia enorme en la historia de Hungría: la política turca se dio cuenca que era imposible seguir su política de dominación indirecta por Hungría y en 1541 ocupó la capital Buda (Budapest, Hungría) estableciendo su siscema administrativo y garantizando así la división del país en cres partes.

17 Para no perder el objecivo de este artículo, sólo menciono las más destacadas publicaciones de documentos: Fernández Alvarez, Manuel: Corpus dacumental de Carlos V. Salamanca, 19731981, 5 vol; ANTON vON GÉvAY: Unkunden und Actenstücke zur Geschichte der Verbälnisse zwischen Österreich, Ungern und der Pforte im XVI, und XVII. Jabrbunderte. Wien, 1840.vol. 1-3; MIHÁLY HAT. VANI: $A$ briajzeli országos levéltár és a burgundi levéltár Monumenta Historiae Hungaricae, Pest, 1857; KARL LANZ: Correspondenz des kaisers Karl V., Aus dem königlichen arcbiv und der Bibliotheque de Bourgogne zu Brïssel mitgetheilt von Katl Lanz, 1 Bd. 1513-1532, 2 Bd.1532-1549, 3 Bd. 1550, Leipzig, $1844-46$.

18 Por ejemplo el capitán del castillo de Estrigonia (Esztergom, Hungría) cuando los turcos lo ocuparon en 1543, era Tomás Lascano. En 1552 al caer la fortaleza de Temesvár (Timisoara, Rumanía) junto con el capitán István Losonczy murieron 300 soldados españoles. En la corte de Viena existía un grupo de presión español con miembros como Juan de Castillejo, secretario privado de Fernando I, Francisco Salamanca, vicecapitán de Estrigonia en 1543, etc. Esta gran cantidad inusual de hispanos en la tierra magyar se debe a la alta admiración que tenía el valor militar de los tercios de España de aquel entonces.

19 El trono lo hubiera ocupado Fernando, en compensación Szapolyai, titulado peyorativamente como eel vaivadan, ya viejo de edad que fue reconocido como rey soberano y hubiera poseido sus cerritorios hasta su muerte mientras los sucesores hubieran recibido el título de Príncipe de Szepes 
posible unificación del país en mano de Fernando, fracasó porque Fernando, para fortalecer su posición y debilitar la de su enemigo, denunció el tratado en la Sublime Puerta. El otro bando tampoco guardaba su palabra, pues despues de que en 1540 había muerto Szapolyai, su hijo recién nacido, Juan Sigismundo fue reconocido por sus partidarios como rey de Hungría. Solimán, para anticipar este acercamiento tan negativo para sus intereses y para preparar el camino hacia Viena, decidió ocupar el corazón geográfico y político del país, la capital Buda (Budapest, Hungría) ${ }^{20}$. Con este hecho no sólo se repartía el Estado debilitado en tres partes, donde el centro turco dificultaba la posible unificación de la región occidental y norteña, en manos de Habsburgo y la oriental Transilvania en mano del bando "nacional», sino que se establecía la administración turca durante 150 años. En estos años apareció en la escena política de los de Szapolyai un talento político, un diplomático hábil: Fray Jorge ${ }^{21}$, siendo gobernador de la parte oriental de Hungría, en nombre del niño Juan Sigismundo Szapolyai, desde 1541 renovaba las negociaciones con el rey Habsburgo sobre la ejecución de la paz de Várad. En 1547 los hermanos Habsburgo firman una tregua de cinco años con la Sublime Puerta, que no tenía validez en los asuntos de Hungría: los turcos no querían tener la mano atada en Europa Central Oriental. La situación interna de Europa y la paz establecida con Istanbul permitían al emperador Carlos V, que en la guerra contra la liga de Esmalkalda acabara con la oposición de los príncipes alemanes. En este ejército imperial participaba el protagonista de este estudio: Bernardo de Aldana y su tercio posterior.

En 1549 en Bátor (Nyírbátor, Hungría) los representantes de Fernando, el capitán supremo conde de Salm, el lugarteniente Tamás Nádasdy ${ }^{22}$ firmaron

(región de la actual Eslovaquía fronteriza con Polonia.) Según el rratado los puntos establecidos hubieran sido declarados sólo en el caso, si el emperador Carlos V gatantizara la defensa milizar de las partes firmadoras de la paz contra la esperada venganza turca. Así la ratificación (que se realizó en Toledo) y el vigor del documento dependía de la decisión del rey español.

20 Un grave error que aparece constantemente en la historiografia española y occidental es llamar la capital húngara Budapest en vez de Buda. Hasta los setenta del siglo XIX existían tres ciudades independientes una de la otra en la otilla del Danubio: Pest, Buda, y Buda Vieja (Óbuda). La capital política era Buda, mientras dutante los siglos Pest se convertía en el centro comercial y bancario. Budapest surgiría sólo después de la unificación. O sea en la Edad Moderna el centro político de Hungría era Buda y no Budapest. (Sólo hago una referencia aparte, que por varias razones, entre ellas por el hecho que Buda fue dominada por los turcos entre 1541 y 1686 , durante los siglos XVI-XIX Buda, junto con Pest estaba competiendo con Posonio (Bratislava, capital de Eslovaquia) por el título de la capital del Reino.)

21 De origen croata, conocido tambien como Jorge Utiesenovič o con el apellido de la madre: Georgius Martinusius, o Martinuzzi en forma italianizada.

22 El alemán Niklas (!) graf zu Salm supremus rerum bellicarum in Hungaria capitaneus El rango de Nádasdy era lockmtenens. In: GÉZA PALlFF: A török elleni védelmi rendszer néhány alapkérdése a XVI. század elsō felében. In: Hagyomány és korszerớśg a XVI-XVII. században. Eger, 1997, 67. (=Studia Agriensia 17.).

Hispania, LX/3, núm. 206(2000) 881-910 
nuevo tratado con Fray Jorge ${ }^{23}$. Realizando el tratado se estableció la ruta militar entre Transilvania y Hungria de los Habsburgo con la ocupación y construcción del castillo de Szolnok (Hungría) sobre la orilla del río Tisza en Hungría oriental. Después de la muerte del capitán supremo $\mathrm{Salm}^{24}$ durante la primavera de 1551 en el mandato del rey Fernando se enviaba un ejército pequeño, alrededor de 7000 soldados (junto con los 1400 españoles del tercio de Aldana), encabezado por il conditierro, enemigo de Aldana, Giovanni Baptista Castaldo ${ }^{25}$. Como mencionan todas las obras dedicadas a este tema, referiéndose al número de los soldados en la expedición del Castaldo: para ser ejército eran pocas, para ser embajada eran muchos. Evidentemente el interés estratégico primordial de los turcos no podía permitir que las dos partes húngaras se unieran en una mano. La división territorial garantizaba la separación de las fuerzas; así se establecía un status quo favorable a la Sublime Puerta. Este ejército, tan reducido en comparación con los ejércitos turcos de 70.000 hasta 150.000 de soldados sólo provocaba la ofensiva ottomana. En estos años entre 1549 y 1552 se mostraría el talento del Fray Jorge, quien en esta situación tan delicada se balanceaba entre la amenza turca de intervención militar y la exigencia e inpaciencia de la concesión y unión territorial de parte de gobierno de Fernando. El gobernador de Transilvania seguía pagando los tributos a los turcos, para apaciguarlos y mantenía una correspondencia muy activa con los servidores del Sultán y con Solimán mismo. Paralelamente informaba de sus pasos a los representantes de Fernando y al rey mismo. Evidentemente los representantes del rey, como Castaldo o Nádasdy (quien por disputas sobre la posesión de bienes odiaba a Fray Jorge) no veían claramente las manipulaciones geniales del gobernador y temían de una posible alianza entre el ejército turco y transilvano, que hubiera significado la muerte de los 7000 soldados entrados en Transilvania. El gobierno hasburgo al haber perdido la paciencia durante el otoño de 1551 mandaba el asesinato de Fray Jorge ${ }^{26}$. Castaldo lo cumplió en Alvinc (Vinču de Jos, Rumanía) el 17 de diciembre de 1551.

La muerte del fraile evidentemente no solucionaba el problema del ejército fernandino. El contraataque de los turcos en 1552 llevaba consigo la ocupación

${ }^{23}$ Los puntos del tratado no difieren mucho de los de Várad. También se exige un ejército razonable para poder oponerse al contraataque furioso de los turcos. Las diferencias más importantes: la concesión del territorio oriental se realizaría en breve tiempo. La viuda reina y su hijo reciben el principado Oppeln y Ratibor en Bohemia.

${ }^{24}$ Entre 15 y 21 de diciembre de 1551.

${ }^{25}$ Según las memorias de Aldana la causa del conflicto entre el italiano y el español, era que durante la guerra de Esmalkada en 1547, el emperador, al escoger un campamento para su ejército aceptó el consejo de Aldana, quien en aquel entonces era sólo capitán, en vez del general Castaldo, ofendido en su orgullo.

${ }^{26}$ Lo más absurdo en la situación que el fray el 20 de octubre de 1551 fue elegido como cardenal, por la petición hecha por su posterior asesino, Fernando I. iCon la muerte del cardenal todos los comprometidos, canto el rey cometían un pecado que les amenazaba con la excomulgación! 
de las claves de Transilvania: Becse (Bečej, Serbia) Becskerek (Zrenjanin, Serbia), Temesvár (Timisoara, Rumanía) Lippa (Lipova, Rumanía), Arad (Arad, Rumanía), y la caída de las fortalezas que conectaban Hungría occidental con la oriental. (Drégely y otras fortalezas al norte de Buda, Szolnok.) Sólo podía defenderse heróicamente el castillo de Eger $^{27}$.

La descomposición del dominio habsburgo en Transilvania no tardaría mucho. Ya desde el invierno de 1553 los soldados de Castaldo abandonaban con o sin el permiso de su capitán general Transilvania. Primeramente saldrían los alemanes, luego los italianos y por último el resto de los españoles ${ }^{28}$.

Los documentos presentados en este artículo completan y precisan los datos del manuscrito de la Expedición de Aldana. En este estudio yo me limito a exponer las mayores diferencias o contradicciones entre las dos fuentes y en explicar el contexto histórico en que se ubicaba el tercio español.

\footnotetext{
27 Drégelypalánk actualmente, Szolnok, Eger- Agria, en Hungría.

28 Sobre la hisroria húngara de estos años véase: JÁNOS ILLÉsY: Adarok a szolnoki vár építéséhez és elsô ostromához. In: Hadłö̀tténelmi közlemények, 6 (1893) 635-666; IMRE SzÁNTó: A szolnoki vár felépítése és a török kézte jutása 1550-52. In: Szolnok váns története. Szolnok, 1975. I.volumen, 39-56. IMRE SZANTó: Küzdelem a török terjeszkedés ellen Magyavországon. Az 1551-52. évi várbáborak. Akadémiai Kiadó, Budapest, 1985; IMRE SzÁNTó: A rörök 1551. évi ószi hadjárata a Temes-vidék és a Maros-völgy meghódítására. In: Hadtörténelmi közleményeke, 1972, 1, 73-96; JENO RóNAI HORvÁTH: Magyar hadikrónika. In: Hadtörténelmi közleményete. 9 (1896); KÁROLY CŹMER: Temesvár megvétele 1551-52, In: Hadtörténelmi közlemények. 1893, 6, 3 publicaciones; LAJOs KROPF: Castaldo Erdélyben. In: Hadtörténelmi käzlemények. 1895, 1896, 8-9. 6 publicaciones; GábOR BARTA: $A z$ erdelyi fejedelemséfy szilletése, Budapest, Magyar História, 1979; GÁBOR BARTA: Az etdélyi Fejedelemség elsó korszaka 1526-1606. In: Erdély története, Budapest, 1988. I. 409-541 En alemán: Kurze Geschichte Siebenbïrgens. Budapest, 1990; En ingles: The Emergence of the Principlaity and its First Crisis (1526-1606). In: History of Transiluania. Budapest, 1994, 247-300; GABOR BARTA: Vajon kiê az ország? Helikon, Budapest, 1988; IGNÁC ACSÁDY: Magyarország három részte szakadásának története 1526-1608, In: Magyar nemzet története, 5. volumen, 1898, 294-321; LÁszLó BárDOssY: Magyar politika a mobácsi vêsz után. Budapest, 1943 [1992] 187-233, 263-339; ÁGNES R. VÁRKONYI: Exropica varietas - bungarica varietas. Akadémiai Kiadó, Budapest, 1994, 10-36. Otros artículos en alemán, inglés y francés: RODERICH Gooss: Österreichische Stadtsverträge. I. Grossfürstentwm Siebenbürgen (1526-1690). Wien, 1911; F. B. voN BUCHOLTZ: Geschicbte der Regierung Ferdinand des Erten. Wien, 1838, 9 tomos. Ferenc SzakÁly: Phases of Turco-Hungarian Warfare before the Battle of Mohács (1365-1526). In: Atta Orientalia Academiat Scientiarum Hungaricae 33 (1979), 65. 111; Ferenc SZAKśly: The Early Ottoman Period, including Royal Hungary, 1526-1606. In: $A$ History of Hungary. Indiana University Press, 1990, 83-99; GEZA DAVID y PAL FODOR: HungarianOttoman Military and Diplomatic Relations in the Age of Süleyman the Magnificient. Budapest, 1994; PÁ FODOR: Ottoman Policy towards Hungary, 1520-1541. Atra Orientalia Academiat Scientiarum Hungaricase 45 (1991), 285-305; IMRE LUKINICH: La catastrophe de Mohács au point de veu de l'histoire militaire. Revue des Études Hongroises 5 (1927), 324-342; GÁBOR ÁGOSTON: Habsburgs and Ottomans: Defense, Military Change and Shifts in Power. In: The Turkish Studies Association Bulletin. Vol. 22, no.1 (Spring 1998), 126-141. Las dos crónicas más destacadas: MikIós IstváNFFY: Magyarország története (1490-1606). Trad.: GYŐßGYY VIDKOVICH, Debrecen, 1871 versión en latin: NiCOLAUS ISTVÁNFFY: bistoriarum de rebus bungaricis libri XXXIV. Colonia Agrippina, 1622.; SEBESTYÉN TINÓdI: Kńnika. Ed.: SUGÁr ISTVẢN, Budapest, 1984.
} 
La correspondencia de Aldana y de su tercio se halla en el Österreichisches Staatsarchiv en Viena, Haus-, Hof- und Staatsarchiv (HHStA), Ungarische Akten (Hungarica) Fasciculus 55-60. Fue encontrada por el profesor Szakály Ferenc, quien durante el mes de noviembre de 1998 me la entregó, para que yo analizara los documentos.

El manuscrito de la Expedición y la correspondencia tiene una visión muy peculiar, la de un mercenario extranjero, sobre los hechos y acontecimientos de Hungría de los años 1548-1552. A pesar de esto es sorprendente lo bien que conocía Aldana la situación política magyar. Sus conocimientos geográficos de esta región lejana también son muy grandes ${ }^{29}$. Tampoco es despreciable su exactitud y solidez en determinar la cronología de los sucesos. Un acontecimiento que figurara en el diario o en las cartas, ocurrió de verdad en aquel lugar y en aquella fecha.

En la correspondencia hay lagunas grandes. No podemos comparar el diario con la correspondencia, por la falta de cartas en los acontecimientos más críticos, como por ejemplo la batalla perdida de Szeged (Hungría) de $1^{\circ}$ de marzo de 1552, donde Aldana encabezaba el ejército multinacional de los cristianos contra el bajá de Buda, o el abandono de Lippa el 28 de julio del mismo año, por lo cual fue condenado con pena de muerte. Sólo disponemos de cartas de 4 de abril de 1549 a $1^{\circ}$ de noviembre de 1551 . Y otra correspondencia de 25 de marzo de 1553 a 22 de septiembre. Mientras la primera contiene en su mayor parte las cartas de Aldana ${ }^{30}$, las de 1553 sólo tratan de los soldados españoles, sublevados por falta de paga sin mencionar a Aldana quien entonces estaba en cárcel.

Lo primero que tenemos que declarar es que el diario por ser escrito y editado después de la muerte de Aldana, sirve eclaramente...la rebabilitación de $\mathrm{Al}$ dana, injustamente calumniado» ${ }^{3 I}$. Este hecho explica también porqué es tan exagerada la presentación del papel y de la personalidad de Aldana. Aparece en las páginas como el talento militar por excelencia y símbolo de prudencia y buen gobierno, incomprendido por los otros capitanes y generales del rey. Además se le opone a esta presentación el enemigo más cruel: Giovanni Baptista Castal$\mathrm{do}^{32}$. Por esas circunstancias no figuran o se han modificado en el diario acontecimientos que hubieran podido salpicar la reputación de Aldana, sirviendo así como argumento y justificación para aquellos que estaban por el juicio y ejecución del maestre de campo.

\footnotetext{
${ }^{29}$ La transcripción de los topónimos húngaros es exacta: Bât, (FLamarch en alemán): Flamarque en las cartas de Aldana; Szitnya: Scitna; Szolnok: Salnoch; Becskerek: Bechquereque, Csanád: Xanade, Szeged: Ceguedin, etc. Los nombres: Bawb: Baxo; Teuffel: Taybel; Kincsi Mibäly: Quincbi Micbal, etc.

30 De las 47 cartas 35 fueron escritas por el maestre de campo. De estas 28 destinadas a rey Fernando I, 3 a general supremo Castaldo, 1 a Fray Jorge.

"SZAKÁLY (1986) 33, passim.

${ }_{32}$ RODRIGUEZ VILLA (1878), passim, especialmente pp. 101-103.
} 
¿Cuáles son estos acontecimientos tan delicados? Primeramente veamos la relación entre Aldana y el general supremo conde de Salm entre 1549 y 1550, año de fallecimiento del último ${ }^{33}$. En 1548 en las cortes de Pozsony (Posonio, Presburg, Bratislava, capital de Eslovaquía) los estamentos llegaron a acuerdo de organizar una expedición contra los oligatrcas Mátyás (Mathias) Basó y Menyhért (Melchior) Balassa, opuestos a la voluntad del rey Fernando. Esta expedición se realiz6 en la primavera de 1549, encabezado por el general supremo conde de $\mathrm{Salm}^{34}$. El ejército constaba alrededor de 5500 soldados, alemanes, húngaros y el tercio de Aldana con 1400 españoles, repartidos en siete compañias. Los vicegenerales eran Reinprecht von Ebersdorf ${ }^{35}$ y Erasmus Teuffel ${ }^{36}$. El jefe de la caballería ligera húngara, de los famosos huzaros era Bertalan (Bartolomé) Horvatinovič, el capitán de la infantería húngara Ferenc (Francisco) Bebek. Y naturalmente los españoles estaban bajo el mandado de su maestre de campo, Aldana. El español estaba subordinado no sólo a Salm, sino a los dos vicegenerales también. A pesar de esto, según el diario Aldana actuaba como co-general de Salm, incluso da la impresión que el conde reconociendo su valor le cedió la gestión de la expedición ${ }^{37}$. La correspondencia precisa la verdadera posición del maestre de campo en la jerarquía militar de la expedición. Los españoles en esta expedición desempañaron un papel muy importante. Siendo la infantería más usada en los asedios, tecaía sobre sus espaldas la tarea más dificil de la expedición: realizar y encabezar los ataques contra los castillos de los oligarcas. El número de los soldados españoles también muestra la inportancia de ellos: 1400 de 5500 en total. Además, el único capitán que era experto en los asedios, en la técnica de artillería era el mismo Aldana. Tampoco son desdeñables sus conocimientos de ingeniería y arquitectura militar ${ }^{38}$. Estos hechos le podrían facilitar una reputación igual o en algunos casos superior a los vicegenerales Ebersdorf y Teuffel. Incluso - según como parece en la correspondencia- durante los asedios el maestre de campo tenía plena libertad y autorización de concluirlos. Supongo que se había formado un mecanismo donde antes del cerco de un castillo los capitanes habían consultado y repartido los deberes. Luego encargaban a Aldana poner la artillería y batir el castillo y organizar el

${ }^{3}$ GEZA PÁlfFY: $A$ császárváros védelmében. A gyóri kapitányság története 1526-1598. Gyôr, 1999. 69; IBID (1997) 67; SZAKÁLY (1986) 17; ISTVKNFFY (1871) [1622] 324, TINÓDI (1984) 355.

34 Sobre la expedición de 1549 véase: TiNód (1984) canción X, Szitnya, Leva Cuábrág és Murán váraknak megveuśse. 351-370; ISTVÁNFFY (1871) [1622], 322-330; AGNES R VÁRKONYI: A rejrōzködõ Murányi Vénus. Helikon Kiadó, Budapest, 1987, 32-33. Expreso mi especial agradecimineto a BÉLA SARUSI-KISS, quien me ofreció los capítulos muy interesantes de su manuscrito monográfico de la historia de la ciudad Murány (Muran, Eslovaquía).

35 Sobre la coincidencia de los capitanes Ebersdorf y Oppersdorf véase: PÁLFFY (1999) 229, 243.

36 IBID. 229,230, 261-263.

37 RODRIGUEZ Villa (1878) passim. p. 52: «... asi lo decian al conde, el cual se tenia siempre al parecer de Aldana."

38 Véase.: SzaKály (1986) 18; Fernández Duro (1824) 270-273. 
ataque. En el ataque fueron utilizados los soldados del tercio, apoyados por los aydoques (infantería húngara) ${ }^{39}$ y por los alemanes. Esta táctica es bien reconocible en el caso de cerco de Murány (Muran, Eslovaquía), donde el general supremo del ejército, el conde de Salm, apenas subió al monte del castillo, sino que se quedó al pie de el, junto con la caballería, para proteger las vituallas y obstaculizar cualquier ayuda a los del castillo ${ }^{40}$. Eso implica también que el general supremo dio mano libre a su subordinado español y le cedió la organización del asedio, reconociéndole como segunda persona de su ejército.

En el diario la relación entre el conde de Salm y Aldana parece ser óptima. La realidad es que hay que matizarlo. La colaboración entre los dos oficiales tiene dos fases, la expedición de 1549 y la construcción del castillo de Szolnok (Hungría) hasta la muerte del primero ${ }^{41}$. La relación entre los dos está llena de tensión durante el año 1549. Este hecho se refleja muy bien en el saqueo del castillo de Csábrág (Čabradsky Vrbovok, Eslovaquía) el 4 de julio de 1549, donde los españoles se sentían indignados, pues aunque ellos habían arriesgado sus vidas junto con los otros, por la toma del castillo, los alemanes y los húngaros saquearon el castillo.

«... a mi me mando [el conde] que quedase fuera del castillo y recogiese todos los prisioneros y los pusiese en un cierto lugar sin que nadie les biziese agravio. Quando yo fui delante del castillo vi entrar los soldados dichos con mucha gente tras ordinaria y vi todo entorno de la muralla llena de aydoques y buzaros y los que estavan en el castillo a muy gran priesa les echaban de la ropa que estava dentro y algunos por el rebellin baxo les davan la moneda con que se ballaban. Yo lo enbie a avisar al conde para que lo remediase para que no sucediese algun error y no solamente no se remedio mas de los propios criados de los que estavan dentro començaron a salir cargados de alguna ropa que dentro avia. Viendo esto los soldados y ballandome yo ocupado con los prisioneros que comengaban a salir determinaron a bazer lo que los otros y entraron por quinientas partes del castillo $y$ ayudaron en saquear... ${ }^{42}$

Aldana fue ofendido por su general, cuando Salm le encargó el cuido de los prisioneros, alejándole así del castillo, mientras el alemán envió sus siervos dentro

\footnotetext{
${ }^{39}$ Aydoque, o bajdú era la infantería semiregular que se aprovechaba por su bravura con mucho éxito contra los turcos.

40 RODRIGUeZ VWIA (1878) p. 54: «Habiéndose quedado el conde con la caballeria toda a punto en lo baxo y babiendo Aldana reconocido todas las estancias de los soldados... bizo tocar una trompa para señal de arremeter.

41 HHStA Hungarica, fasc. 56 fol. 80. Aldana a Fernando I a 15 de diciembre de 1550, Agria (Eger; Hungría), fol. 87, Aldana a Fernando I a 21 de diciembre de 1550, Agria. La carta de 15 de diciembre manifiesta la esperanza de Aldana en la recuperación de Salm, mientras la siguiente ya comenta la muerte del conde. Véase: RODRıGUEZ VILIA (1878) 71; SZAKÁlY (1986) 124; PÁI.FFY (1999) 70, 229, 258. Estas dos cartas precisan la opinión de PÁLFFY, que Salm falleció «antes de 26 de diciembre». conociendo la precisión de Aldana me atrevería a suponer que la muerte del conde habría podido ocurrir el 19020 de diciembre.

${ }_{42}$ HHStA Hungarica, Fasc. S5, fol. 23-24. Bernardo de Aldana a Fernando I a 5 de junio de 1549, Csábrág. Compárase RoDriguEz VILIA (1878) 48-49.
} 
para recoger algunas riquezas. El general quería compensar y apaciguar más tarde a Aldana y se le concedió la vida y bienes de los castellanos de Csábrág Ferenc (Francisco) Nyakazó y Mihály (Miguel) Kincsi.

-Estando escribiendo esta creo que a arrepentido el conde de la furia pasada me a enbiado a dezir que envie a suplicar a Vuestra Majestad que me baga merced de las vidas, libertad y ropa de Nachossio Fereng y Quinchi Michal, castellanos deste castillo porque me ayuden alguna poca de mi empresa $a^{4{ }^{3}}$.

Causó un conflicto tan grande aquella riña entre los españoles, alemanes y húngaros, que terminó con la muerte de algunos de ellos. Los españoles se enojaron por los acontecimientos mencionados de Csábrág y porque después de la toma del castillo desaparecieron 35-40 caballos. Los soldados hispanos, junto con Aldana acusaban a los húngaros. Salm descargaba la responsabilidad sobre supuestos martaloces ${ }^{44}$, que hacían incursiones desde las tierras turcas. Más tarde los españoles detendrían a unos alemanes y húngaros, acusándoles del tobo de los caballos. Pero el general los soltó. La desconfianza de parte de los españoles a su general alemán poco a poco aumentaba. Le acusaban de parcialidad hacia los húngaros y de blandeza. En cuanto de la parcialidad podían haber tener cierta razón, pues la mujer de Salm era la hija del noble húngaro Elek (Alejo) Thurzó, socio de negocios de los Fugger en las minas húngaras de plata y de cobre. Además era conocido que Salm disfrutaba de una simpatía única entre los generales extranjeros del rey Fernando.

Cuando pocos días después de la riña, los soldados españoles se amotinaban por las anomalías de las pagas, el conde intentaría apaciguarlos, sin ningún resultado. Sólo obedecían a las palabras de su maestre de campo, quien había vuelto del reconocimiento del castillo de Murány, como subraya con fina ironía Aldana en una carta posterior.

"Estando sobre Xabracb nos hurtaron basta treynta y cinco o quarenta cavallos de los nuestros y mataronnos y prendieronnos basta catorce o quinze moços. Y entre la gente comunmente se pensava que eran nuestros propios bungaros porque bazia la parte de su quartel se bazian estos daños. El conde nos certificaba que no, sino que eran martelosos que venian de las tierras de los turcos y yo quisiera trasnochar un par de noches y darles la buena respuesta pero el conde no lo consintio por respeto de las treguas ${ }^{45}$ (...) siempre crecia la suspension y odio de los españoles con los bungaros pareciendoles que si ellos no lo bazian que era consentimiento suyo. Sucedio en este medio un dia que el conde y yo fuymos a Scitna que un alabardero suyo se revolvio con un español sobre unos moços que tenian y ocuriendo gente de una y de otra parte fue muerto un atabalero del conde y otro soldado bungaro y otros dos beridos $y$ de los españoles fueron tres muy mal beridos. Pero luego se aquieto la cosa y yo prendi dos de los que tenia ynformacion que tenian parte en

\footnotetext{
${ }^{43}$ Ibid.

${ }_{44}$ Martaloces: tipo de soldados irregulares, quienes servían no sólo en el ejército turco, sino en el húngaro.

${ }^{45}$ Firmada en 1547 para 5 años.
} 
esta culpa al uno dello, el menos culpado pensava castigar mas asperamente en baziendole suficiente ynformador pero en la fiesta que bezimos al Corpus Cbristit 10 demandaron algunos soldados al conde y el me lo mando soltar. Yo le avise que mirase lo que mas dava pero el se resolvio en ello y yo le obedeci como mi general. (...) fuymos la vispera de San Juan ${ }^{47}$ a dos aldeas legua y media de Xabracb. En la una alojabamos a los españoles y en la otra el conde con los uzaros y gente armada. En esta noche dos oras antes del dia se toco un arma en el casar donde yo estava a la qual yo sali luego y quiriendo recoger diez 0 doze arcabuzeros que vi juntos dispararon dos los arcabuzes y a mi sargento que yba conmigo le llevaron dos dedos de la mano y yo ballandome tan cerca de uno de aquellos soldados que no pude bazer otra casa le di dos o tres beridas de las quales murio pero viendo que la cosa era de mala decision retireme a mi posada y avise a los capitanes y vanderas para que se recogiesen a un cierto lugar. $Y$ algunos de aquellos vellacos fueron multiplicando basta dozientos los quales fueron derechos al (!) artilleria donde estava de guardia Luis Ordoñez con su compañia y ansi mesmo se avia recogido la de Luis de Barrientos y tirandoles muchos arcabuzazos de los quales birieron un cabo de escuadra de Luis de Barrientos les bizieron apartar de alli. Yo les envie a mandar que fuesen todos los que pudiesen pasar al casar donde el conde estava y ansi lo bizieron. La demas gente ecepto los dozientos que tengo dicho se recogio conmigo con sus banderas diziendome que les mandase lo que avian de bazer. En este medio yo enbie algunas personas a bablar a estos mal aventurados enbiandoles a dezir las cosas que me parecian que convenian al servicio de Vuestra Majestad y respondieron me a todo dos cosas barto feas. La una que yo no les dexava ganar y aprovechar en las tierras de Melchior Balax y a sus aliados aviendolas conquistado y la otra que yo les avia bablado dos dias pasados que soltasen media paga para ayudar a entretener la compañia que se recibia de Luis Ordoñez. Y que no embargante que ellos avian sido contentos de soltalla que despues aca avian sabido que lo avia becho por quedarme con esta media paga que se la diese juntamente con otras dos que se les debian en fin deste mes de junio. Yo les respondi que estavamos a una legua de los turcos donde se nos podia por nuestra occasion suceder un gran peligro en desservicio de Vuestra Majestad y ansi mesmo grandisimo escandalo entre los bungaros de quien nos aviamos de prevalecer $y$ ayudar $y$ que se recogiesen a sus vanderas $y$ si algo avian de aver que se les daria ${ }^{48_{\infty}}$.

El orgullo del maestre de campo fue otra vez ofendido, cuando al haber caído Murány las segundas personas en la jerarquía de los del castillo, como el hermano del oligarca Mátyás Basó, Domenico, el castellano Ferenc Tárnok no fueron entregados a Aldana, para obtener un rescate e ingreso de la vida de ellos, sino el conde mandó a decapitarlos. Salm argumentaba con mucha razón, que el enemigo de los hermanos Basó, el capitán Bebek ${ }^{49}$ exigía la muerte de ellos y por eso los hizo ejecutar. Esa respuesta escandalizaba al español, puesto

4620 de junio de 1549 , jueves.

$47 \mathrm{O}$ sea 23 de junio, domingo.

49 HHStA Hungarica, fasc. 55, fol. 25-26. Bernardo de Aldana a Fernando I a 26 de junio de 1549, a cuatro leguas de Csábrág.

49 Bebek cenía tierras en las regiones cercanas a las de Basó. 
que el general alemán preocupaba más por la voluntad del húngaro, jefe de las tropas auxiliares, que por los intereses de Aldana, jefe de los soldados más potentes del ejército contra los oligarcas.

*...el conde me enbio a dezir con un capitán de ungaros que le enbiase los prisoneros que yo tenía (...)Yo se los enbie luego y le enbie a dezir que de las faltas que me bazian los bermanos de Matias Basso que yo no me curava aunque fuera muy mayor cantidad pues que el me avia dicho que convenia al servicio de Vuestra Majestad cortalles las cabeças juntamente con su bermano pero que la de Estorno que la reservase si al servicio de Vuestra Majestad no ymportava otra cosa. (...) Enbiome a dezir el conde que el quisiera mucbo aver salbado la vida de aquel por mi beneficio pero que no lo avia podido acabar con el Bebech con menos palabras que dara contento diziendo que convenia al serbicio de $V$ uestra Majestad. Pero desto fuera a me pesado mucho que el conde tenga a nadie mas respecto que a mi maxime que el sabe que la onra que mis trabajos le an becho ganar en estas enpresas no se lo bubiera becho ganar el Bebech y aunque por mi necesidad no me pesa porque se que sirvio a Vuestra Majestad que no me la dexara pasar... ${ }^{50}$ "

Tampoco disminuía las tensiones el modo como dejó el conde a Aldana mandándole que pusiera en orden el castillo, poniendo en él las vituallas y la batería, sin que le hubiera facilitado los carros y vitualla necesariasi.

A pesar de los conflictos surgidos entre el capitán supremo y Aldana, en la correspondencia el español siempre reconocía la superioridad de su jefe, mientras el diario nos proporciona una impresión, como si el alemán y el español hubieran tenido el mismo rango, incluso como si el primero hubiera estado pendiente de los superiores conocimientos militares del último.

La relación de los dos oficiales durante el año 1550 se parece más a lo insinuado por el diario: las tensiones disminuían. En la correspondencia de Aldana ni aparecía aquel resentimiento que se había manifestado antes. El secreto de la buena cooperación de los dos radica en que Salm, como general supremo de la expedición que había adelantado a los turcos en la toma del castillo vacío de Szolnok (Hungría) residía en Agría (Eger, Hungría), y de allí visitaba a su subordinado español quien se ocupaba de la reconstrucción del castillo de Szolnok; o sea en la falta del contacto cotidiano. En la ocupación de Szolnok fueron mobilizados más de 10000 soldados, repartidos en diferentes castillos de la región, donde el tercio español tenía menos dominación militar, como en la expedición de 1549. En la jerarquía militar encima de Aldana se encontraba el mismo Salm, Ebersdorf, Teuffel quienes habían sido jefes de él en 1549 y también el lugarteniente húngaro, Tamás (Tomás) Nádasdy.

El diario menciona la muerte del conde Salm ${ }^{52}$, como una pérdida inapreciable de un militar extraordinatio, quien siempre se había llevado bien con los

${ }^{50}$ HHStA Hungarica, fasc. 55, fol. 52-54. Bernardo de Aldana a Fernando I, a 16 de agosto de 1549, Murány.

51 HHStA Hungarica, fasc. 55, fol. 56-57. Bernardo de Aldana a Fernando I, a 25 de agosro de 1549, Rimaszombat (Rimavská Sobota, Eslovaquia).

32 Véase noca 41. 
españoles, y por esta razón todos los soldados estaban de luto ${ }^{53}$. Comparándolo con el diario es chocante la indiferencia que manifestaba Aldana al haber escrito sobre la muerte del alemán. Después de las primeras frases dedicadas al fallecimiento de su general, el maestre de campo se preocupaba más por las pagas y por el reforzamiento con cañones, del castillo de Eger y Szolnok. Como conclusión, se podrá decir que la relación entre Aldana y Salm no fue tan rosada y óptima como parece manifestarse en el diario.

Surge la pregunta: ¿́por qué ocultaba el escritor del diario la verdadera relación entre los dos? En los tiempos del juicio de Aldana no dan lo mismo las formas de relaciones que existían entre el general supremo de siempre y su subordinado, el maestre de campo. Al público ${ }^{54}$ y a la élite política, enterada del asunto de Aldana, le diera una impresión absolutamente distinta un subordinado insociable e incompatible con sus generales, como un genio militar, no comprendido por el general sin talento (o sea Giovanni Baptista Castaldo, sucesor de Salm y enemigo de Aldana), quien incluso por celos hacia su subordinado no le reconoce y pretende acabar con éls5. Mientras su ex-general, respetado por los húngaros y alemanes (Salm) se lleva sin conflictos con él, incluso acepta los consejos de su subordinado y así logra triunfar en sus empresas, según las sugerencias del diario. La realidad, como hemos visto, parece no justificar el diario.

Del diario se omitían unos acontecimientos con mucha resonancia. Entre la toma del castillo de Csábrág en 4 de junio de 1549 y la llegada de Aldana con dos banderas al castillo de Murány el 4 de julio, pasaba un mes. La distancia en linea directa es de $80-85 \mathrm{kms}$. Ni las malas condiciones de los caminos, ni el camino real, más largo que $85 \mathrm{kms}$. explican la causa de esta demora tan grande. En este intervalo sucedían cosas que podrían servir como justificación contra Aldana, acusándole de blandura e incapacidad de dirigir un ejército, y reforzando la acusación de lesa majestad, con la que se había incriminado por haber abandonado Lippa ${ }^{56}$.

Hacia finales del mayo - como se trasluce en la correspondencia- los precios se aumentaron, en comparación con los fijados por el gobierno. La paga tenía ya cierto retraso. El dinero de que disponían los soldados no les bastaba para mantenerse e incluso estaba en vigor la orden hecha en Rajka (Ragendorf en alemán, Hungría), según la cual a los soldados españoles se les prohibía saquear las tierras del rey, como los mercenarios lo tenían por regla general.

\footnotetext{
33 SZAKÁLY (1986) 124, RODRIGUEZ VILLA (1878) 71: «...Al conde se le agravó la enfermedad de manera que murio, cuya muerte sintio mucbo Aldana y los españoles, que cierto eran del muy acariciados y bien tratados.*

${ }^{34}$ No olvidemos que el objeto del diario, publicado después de la muerse de Aldana, era la rehabilitación de su protagonista.

35 Véase nota 25.

36 SZAKÁLY (1986) 251-256, RODRIGUEZ VILLA (1878) 98-103.
} 
*...la gente esta muy quexosa y desabrida por ver la poca orden y descuido que casi en todas las cosas se tiene y principalmente en lo de las vituallas porque ai pocas y ruines y caras es traido en tierra tan abundante y siendo el exercito tan pequeño que de razon no devrian de faltar. $Y$ los que mas faltan en este padecer son los españoles porque como an de estar ordinariamente cabe el artilleria $y$ en sus guardas y trincheras no pueden ir a buscar vituallas, otra parte ni seria razon que fuesen como bazen los buzares y los baidones ni tampoco les darian licencia para ello antes les bazen pagar el beno para sus cavallos y paga en que duermen y para solamente pan a menester bambre por lo menos dos cruzados al dia y de vino por poco que beva cuatro cruzados y medio y con todo esto muy ruin y poco de lo cual echan la culpa asi capitanes como particualres al general ${ }^{57}$.

$\mathrm{Y}$ como ya se ha mencionado, los del tercio español tampoco podian participar en el saqueo del castillo de Csábrág.

"Alargados que seamos la vuelta de Moran sucedera el inconveniente que ya e escrito a Vuestra Majestad sobre las pagas. Sera necesario que Vuestra Majestad ponga el remedio para que puedan venir a tiempo si an de venir de Viena porque las vituallas tenemos muy caras y muy diferente de como Vuestra Majestad nos las mando dar y los soldados padecen necesidad.... 58

Estas circunstancias causaban dos tipos de conflictos, por una parte el sobredicho entre los españoles y el resto del ejercito, que el 19 de julio conduciría a un choque armado con muertos: Los soldados insatisfechos por el alza de los precios y por la demora de las pagas se enojaron con los huzaros y hayduques, entre quienes el cumplimineto de la prohibición de saqueo no tenía ninguna eficacia, siendo soldados menos regulares (huzaros) o irregulares (haydoques) ${ }^{59}$. Por otra parte hubo un conflicto entre el maestre de campo y sus soldados, que se manifestaba en dos motines consecutivos la noche de 24 de junio y el 4 de julio $^{60}$. Las causas de estos dos motines fueron los problemas de la falta de paga, aumento de precios. La demora de la paga ${ }^{61}$ y prohibición de saqueo se completaban con otra tensión: Aldana en Rajka había mandado al capitán Luis Ordoñez que reclutara 200 soldados más en Italia, completando así el tercio con 1400 personas. Esta compañía se unificó con su ejército durante el asedio de Szitnya (Sitno, Eslovaquía), a finales de marzo de 1549. Los españoles fue-

57 HHStA Hungarica, fasc. 55, fol. 39-40, Bernardino de Meneses a Fernando I, 24 de julio de 1549 , Viena.

58 Véase.: SZAKálY (1986) 62-64. RodRIGUEZ ViLLA (1878) 32. HHStA Hungarica, fasc. 55 fol. 23-24, Bernardo de Aldana a Fernando I a 5 de junio de 1549, Csábrág. fol. 25-26; Bernardo de Aldana a Fernando I a 26 de junio de 1549, Csábrág y otras, fol. 59, 60-61, 62. sin fecha y sin lugar.

59 Véase las cartas de la nota 58.

60 Véase nota 58.

61 Aldana de Léva (Levice, Eslovaquia) mandó una carta (HHStA Hungarica, fasc 55, fol. 1314. 3 de mayo de 1549) al rey Fernando en que anunciaba a Su Majestad que la marcha a Murány podría causar dificultades en la paga, si no se supera la distancia duplicada con el uso de dos contadores, en vez de uno; o con el depósico cercano del dinero. 
ron repartidos en 7 banderas o compañías (la correspondencia usa ambos términos con el mismo sentido). Para el abastecimiento y paga de los 200 recién venidos Aldana pedía una media paga, con la promesa de que más tarde se lo devolvería. El 4 de julio, cuando a los del tercio se les daba la paga del mes de mayo y junio, ciertos soldados exigían también la del medio mes, prestado a los 200 de Ordoñez y requerían el consentimiento de Aldana al libre saqueo de las tierras vecinas ${ }^{62}$. Según la relación del maestre de campo nos parece que acabó resolutamente con los soldados, haciendo compromiso con ellos, según el cual la media paga sería pagada lo más pronto, pero a los que intentarían saquearse les condenaría lo más severamente ${ }^{63}$.

La confesión de Aldana, que si hubiera podido hacer, no hubiera escrito a Su Majestad, Fernando sobre los motines y conflictos arriba mencionados, y sólo lo hizo, porque alguién podría informar al rey, de manera contraria a la versión del maestre de campo, nos implica que los motines se consideraba comunmente como un gran desprestigio. Por esa misma razón no podían aparecer estos acontecimientos en el diario que tenía como objeto la tehabilitación de su héroe.

"Aca son sucedidas algunas cosas de las quales yo no pensava dar noticia a Vuestra Majestad por ser generales en los exercitos pero el conde me a avisado que de todas las cosas por ligeras que sean ay personas que dan noticia a Vuestra Majestad y a las veces muy diferentes de la verdad y que por tanto seria mejor que yo escriviese la certenidad de lo que pasava para que a Vuestra Majestad no le yndicasen algunas malas ynformaciones64

Entre las acusaciones destaca la blandura de Aldana ${ }^{65}$. Se necesitan más matices para aclarar en qué consistía: El español parecía ser blando cuando por primera vez se enfrentaba con los turcos en la batalla de Szeged (Hungría) y estaba dirigiendo un ejército multinacional, sin ninguna experiencia del jefe individual. Según mi parecer la derrota se debe más a que Aldana, como maestre de campo no estaba acostumbrado a coordinar diferentes tipos de ejércitos y de modos de combatir. En este sentido es aceptable la acusación con la blanu-

62 HHStA Hungarica, fasc 55, fol. 27-28, Bernardo de Aldana a Fernando I, 4 de julio de 1549, Murány. En esta carta se nos aclara que la media paga equivalia a 3.000 florines de oro. LAjos THALLÓCZY mostró que en 1549 el presupuesto de las tropas en campo había sido 205.752 florines anualmente. El tercio español junto con sus oficiales, costaba 78.720 florines al año, o sea 6.560 florines al mes, al gobierno habsburgo. De los 3.000 florines, pagados a comienzos de agosto junto con la paga normal, no recibían los que se habían unido con el tercio después de Rajka, o sea los 200 de Ordoñez, tampoco los oficiales. Los dacos de Thallóczy concuerdan con los de la correspondencia. Véase: THALLÓCZY LAjOS: A magyar hadiköltségek 1549-ben. In: Századok, 1877, 169-172.

${ }^{63}$ HHStA Hungarica, fasc 55, fol. 27-28. Bemardo de Aldana a Fernando I, 4 de julio de 1549, Murány.

64 HHSta Hungarica, fasc 55, fol. 25-26. Bernardo de Aldana a Fernando I, 26 de junio de 1549, Csábrág.

6s Véase nota 56. 
dra ${ }^{66}$. De manera similar, en Lippa (Lipa, Rumanía), Aldana como capitán de un castillo dirigía una fuerza de defensa multinacional y de muchos tipos ${ }^{67}$ en un castillo con reconstrucciones aun no acabadas y con falta de municiones y vituallas ${ }^{68}$. En este caso sería más dificil acusar al maestre de campo con blandura, pues sólo las circunstancias dificultan la defensa de tal manera que no puede imponer su voluntad sobre los soldados de diferentes naciones en una tierra ajena, en un castillo no terminado. Pero la tapidez, con que acaba Aldana con los motines de los españoles en junio de 1549 contradice absolutamente al carácter de persona blanda, tan divulgada en la historiografía húngara. Según mi opinión, podríamos acercarnos más a la realidad en cuanto a la personalidad del maestre de campo si declararíamos que él es persona muy apta para dirigir un tercio de soldados de su nación, subordinado a un general, o para cumplir sus deberes como artillero o arquitecto. Pero fracasa y sería irresoluto cuando debe encabezar un ejército mixto no sólo en la táctica sino en idiomas hablados por los soldados, en un territorio desconocido, con un cargo de mayor individualismo y responsabilidad, como capitán de tropas en campo, o capitán de un castillo.

La tragedia personal de Aldana radica en su ambición, quiere ser más de lo que permitan sus capacidades. La correspondencia nos da la respuesta ¿por qué pretende medrar? ¿Por qué entra en conflicto abierto con Castaldo y con su colega en el capitaneo de Temesvár (Timisoara, Rumanía), István (Esteban) Losonczy? El 15 y 27 de abril de 1549 él escribió a Fernando I, suplicándole que el monarca interviniera ante Carlos I, su hermano para conseguir alguna merced:

"Y ansi suplico a Vuestra Majestad pues que todos los maestres de campo al presente ay del emperador tienen abitos de las ordenes de Alcantara o Santiago o Calatrava que Vuestra Majestad me favorezca para que yo participe de la mesma autoridad siendo servido de escrevir a Su Majestad por un abito de la orden de Alcantara para mi, siendo Su Majestad servido de concedelle mediante las provanģas y diligencias que los bijos dalgo (l) que los demandan an de bazer y esta merced suplico a Vuestra Majestad si es posible alcangarse fuera de la consulta general porque lo que se remite a consulta esta a dos dedos del dia del juiziow ${ }^{69}$.

66 SZAKÁLY (1986) 18-19. RODRIGUEZ VILA (1878) 94-96, 98-103. El crítico húngaro acusa a Aldana, basando en las circunstancias de la batalla de Szeged y Lippa. Véase también la descripción de la batalla: 191-202.

${ }^{67}$ Alemanes, españoles (solo 300), húngaros a pie y soldados los que no querían encerrarse en un castillo por motivos de manera de combatir, como la caballería ligera húngara, o sea los huzaros y los racianos, soldados irregurales a pie. En el castillo de Lippa o alrededor de él había más de 2000 soldados. La caballería y los racianos no estaban dispuestos de servir en un castillo encerrado.

69 Véase SzAKÁly (1986), 19-26, véase también la caída de Lippa: 209-246. RODRIGUEZ VILLA (1878) 94-96.

${ }^{69}$ HHStA Hungarica, fasc 55, fol. 7-8, Bernardo de Aldana a Fernando I, 15 de abril de 1549, Szebeléb (Sebechleby, Eslovaquia). El traductor Scholz y Szakály en el manuscrito han trans- 
No sabemos si se cumplió algo de esta petición, pero como Aldana durante el año 1551 continuamente intrigaba contra Losonczy para conseguir el mando de capitán de Temesvár o más tarde insistía en el de Gyula (Hungría) o Lippa, sugieren que no se hizo nada en cuanto a lo de los hábitos de las ordenes militares $^{70}$. Aunque él disponía de una tenencia de 100000 maravedíes en Sedella, España, pero para conseguir la honra necesaria en la sociedad española, no le satisfacía.

"...enbio en memoria al secretario Castillejo ${ }^{71}$ para que Su Alteza me mande enbiar en España cien mill maravedis de que Su Majestad me bizo merced en la tenencia de Sedella en la consulta pasada y aunque en España no se pagan las tenencias sino de tres en tres años o veramente por favor particular suelen de tener respeto a los que estan ausento en servicio de Su Majestads ${ }^{72}$,

Su orgullo y ambición le conducían a la aceptación de una tarea insolucionable, la defensa de Lippa mal protegida ante de un ataque turco, bien provisto.

Una etapa muy discutida de la expedición de Aldana, fue la reconstrucción del castillo de Szolnok. ${ }^{73}$ El diario nos sugiere como si la conquista de Szolnok y su remodelación hubiera sido obra ejecutada por los españoles, encabezados por su maestre de campo. Szakály en el prefacio del diario lo puso en duda, llamando la atención en que la empresa de Szolnok había sido mayor, para que se realizara según los planes improvisados de Aldana ${ }^{74}$. El crítico tiene razón en que la empresa de Szolnok era mayor para que el peso de defender y construir radicara sobre 1400 soldados. Alrededor de Szolnok se ubicaban más de 10000 soldados de diferentes naciones. En la obra se mobilizaba a los campesinos de las comarcas, trabajaban también arquitectos y carpinteros italianos y bohe-

crito al sitio de Clive, como Szebeléb. La distancia dada por Aldana (Clive está a una legua de Csábrág y una media de Szitnya, véase pp. 317-318 de la versión húngara) afirma la lógica de los dos. En esta carta citada figura Cline, sin duda alguna. El escribano utilizaba otra forma para la $n$ y para la $k$ ov. Incluso en la hoja alguien más tarde anotó Keleny (Klečany, Eslovaquia). Pero la distancia entre Keleny y Szitnya es la doble de la de Szebseléb, hacia la misma dirección, suroriente.

70 SZAKALY (1986) 29, passim.

${ }^{71}$ El secretatio español del rey Fernando I entre 1539-41 era Cristóbal de Castillejo y de 1541 a 1554, Juan de Castillejo. Véase: Thomas FellNer - HeinRICH KreTschmasyr: Die österreichische Zentralverwaltung. Abt. I. von Maximilian I. bis zur Vereinigung der österreichischen und böhmischen Hofkanzelei (1749). Bd. 2. Aktenstücke 1491-1681. Wien, 1907. (=Veröffentlichungen der Komission für neuere Geschichte Österreichs 6.) 159,164,171,175.

72 HHStA Hungarica, fasc. 55, fol. 13-14. Bernardo de Aldana a Fernando I, 3 de mayo de 1549, Léva. Compárase: SZAKÁlY (1986) 29.

${ }_{73}$ De la correspondencia se puede reconstruir cierta parte de la conferencia hecha en Eger (Agria en latín) a mediados del verano de 1550 sobre la ocupación de Szolnok. Los turcos durance la primavera de 1550 habían hecho ciertos preparativos en Szeged y en Buda para ocupar el castillo de Szolnok en la tierra de nadie. La inteligencia del capitán de Eger, István (Esteban) Dobó informaba al corte en Viena. El gobierno habsburgo hacia preparativos acelerados para adelantar a los turcos. La táctica fue acepcada en la conferencia mencionada.

74 SZAKÁLY (1986) 38. RODRIGUEZ VILLA (1878) 62-68. 
mios ${ }^{75}$. Pese a esto yo supongo que el papel de Aldana es superior a lo comunmente pensado en la historiografia húngara. Los capitanes de Szolnok etan Ferenc (Francisco) Zay y János (Juan) Balassa ${ }^{76}$. Aunque el español de ninguna manera era el jefe del castillo, como intentaba demostrarlo el diario, su papel en la fortificación podría ser extraordinatiamente importante. Algunos datos indican que hasta la llegada de los arquitectos profesionales y despachados por la corte, durante dos meses (desde los mediados de septiembre) el responsable por la fotificacción era Aldana. Los arquitectos encabezados por Giovanni Maria de Specia Casa llegaron sólo a mediados de noviembre, cuando el maestre de campo había ya dejado a Szolnok por el orden de Salm y se fue a $\operatorname{Eger}^{77}$. Hasta aquel momento no disponemos de fuentes, que informaran sobre otros posibles arquitectos oficiales. Los sobredichos podrán ser justificados también con la formación de Aldana quien era conocido no sólo como un artillero famoso, sino como arquitecto también ${ }^{78}$. En este periodo las cartas del maestre de campo entraban en detalles profesionales minuciosos ${ }^{79}$. Como contraprueba podría confirmar mis argumentos la cortespondencia de Salm quien varias veces visita la fortificación y expresa su opinión de los planes de Aldana ${ }^{80}$. Pero en sus cartas dirigidas al rey sólo mencionaba a parte que la construcción iba bien, sin entrar en detalles. Clato que ni necesitaba eso, puesto que no era su profesión, ni tarea, dirigir la construcción, sino controlarla ${ }^{81}$.

75 SZAKÁLY (1986) 38.

7625 de octubre de 1550, Fernando informó a la Cámara Húngara en Pozsony (Bratislava, Eslovaquia) que había nombrado como capitanes a los susodichos. ILLÉsY (1893) 635-666; SZর́NTó (1975) 39-56; Compárase: SZAKÁLY (1986) 124. RODRIGUEZ VIILA (1878) 66.

7y Sobre los arquitectos italianos en Hungría y los del Szolnok véase: ENDre Marosi: Itáliai hadiépítészek részvétele a magyar végvárrendszer kiépítésében 1541-92 közört. In; Hadtörténelmi käzlemények. 1974. 45, 67. Según Marosi el atquitecto Specia Casa obraba en Szolnok durante los años 1550-51. El diatio menciona sin nombre la llegada de los arquitectos italianos, quienes llegaron cuando Aldana había dejado en su lugar a su primo Francisco de Aldana y se había ido a Eger. In: SzAKÁLY (1986) 124, Compárase con la carta 35, fol. 80.

78 Véase SZAKÁLY (1986) 18-19.

79 Véase HHStA Hungarica, fasc 56, fol. 48-50, 57, 70, 80, 87. Cartas de Aldana a Fernando I, fechadas de Szolnok entre 30 de septiembre de 1550 a 21 de diciembre del mismo año. Compárase: RoDRIGUEZ VILIA (1878) 66-67.

${ }^{80}$ Tanto en el diario (116), como en la correspondencia se menciona que a Salm no le gustaba una torre en la parte del río Zagyva y la reconstruyeron:

*...Despues aca be buelto aqui con el conde al qual le a parecido bien el disigno que yo quede aqui comensado del foso del un agua a la otra y los dos bestiones (I) que lo acompañan y ansi en la perficion desto se labra de dia y de noche y se da toda la priesa que es posible. El otro bastion y parapeto que yo pensava bazer por la parte del rio Zagyva [Zagyva, río que desemboca en Tiscia o Tisza en Szolnok] para dexar el castillo en treangulo no le a parecido al conde que por este inviemo sera posible por mucba tierra que se avia de cortar para dexar el parapeto en una derecha y por tanto bemos determinado que se baga un parapeto sodo en tormo como el rio corta la tierra." HHStA Hungarica, fasc 56, fol. 48-50, Bernardo de Aldana a Fernando I, 30 de sepriembre de 1550, Szolnok.

${ }^{1}$ Sobre las carcas de Salm véase: ILLÉsY (1893) 646-647. 
Con todo esto no comparto la opinión del diario de que la fortificación era obra de los españoles, sino he intentado matizar y puntualizar los dos polos tan oponentes de diario y de la historiografia húngara. La verdadera importancia de la actividad del maestre de campo la podemos entender si pensamos en que la tarea del ejército real era que antes de que el invierno llegara habran de dejar el castillo en forma defendible, aunque no fuera completo. Esa podría ser la responsabilidad del maestre de campo, con sus planes improvisados. Esta tarea fue cumplida bajo la protección del ejército real y con la gestión del español. La llegada del equipo de Specia Casa era el comienzo de la segunda fase, donde ya los arquitectos profesionales y con renombre realizaban una construcción más profunda y duradera. Esta segunda fase se alargaría más de un año.

La expedición de los turcos de 1551 se refleja de manera distinta en las dos fuentes sobre Aldana ${ }^{82}$. Las cartas —en comparación con el diario- representan obligatoriamente un punto de vista más reducido, provincial. El del vicecapitán del castillo de Temesvár importantisimo para la defensa de Transilvania. Mientras el diario - escrito años después de estos acontecimientos-conociendo los interiores de la política de los Habsburgo en Transilvania, incorpora la política de Castaldo, de Fray Jorge. La correspondencia se dedica sólo a los sucesos militares de la región vecina al castillo, mencionando la "gran" política en generalidades, como por ejemplo Fray Jorge que no era digno de confianza, etc.

La novedad de estas cartas son los capítulos sobre la defensa de la comarca Temesvár, clave de Transilvania, contra el ejército del belerbey de Rumelia, Mohamed Sokolu ${ }^{83}$. Aldana elaboraba un plan completo para la defensa de la región, basando en la fortificación y reconstrucción de Becse y Becskerek ${ }^{84}$. Hacia los comienzos de septiembre el maestre de campo realizó un reconocimiento en compañia de sus soldados y del arquitecto Segismundo Pretta de Pisa ${ }^{85}$. El vicecapitán de Temesvár, transgrediendo su competencia, sustituyó al

82 Aldana fue nombrado como vice-capitán de Temesvár el 12 de agosto de 1551 . Sobre el rango de Aldana y su relación con el capitán Losonczy véase: SZAKÁLY (1986) 17.

a3 Belerbey de Rumelia: El gobernador de las tierras turcas en Europa. El nombre Rumelia deriva de la forma turca de Bizancio, o según la mentalidad ortodoxa y turca: la segunda Rorna, heredador del Imperio Antiguo de Roma.

${ }^{84}$ Los planes detallados de la fortificación: HHStA Hungarica, fasc. 59, fol. 20, 30. Extractos de las cartas de Aldana, escritas en septiembre de 1551.

${ }^{35}$ Véase SzAKály (1986) 148; Sobre la actividad de Pretta de Pisa, como arquitecto de Temesvát y Lippa: Marosi (1974) 67; Sobre la cobardia de Sigismundo Pretta Pisa: HHStA Hungarica, fasc. 59, fol. 30; En la carta fasc. 60, fol. 87. Bernardo de Aldana a Fernando I, 27 de septiembre de 155I, Ternesvár figura lo siguiente:

-...Bien veo que considerarian que están los enemigos a siete leguas de aqui con cincuenta mil bombres y 15 piecas de artilleria gruesa cincuenta de campaña según nos a informado el que llevo al Belerbeg Las letras de Vuestra Majestad para el turco. Tadavia emos dado tal priesa con nuestro trabajo que emos becho un bastión razonable en la parte más flaca de la cibdad y guarnecido cerca cien pasos de muralla por Sigismundo. Me a pedido licencia para irse desde el dia que se fue el señor Batere [András Báthory] protestándome cuanto daño

Hispania, LX/3, num. $206(2000) 881-910$ 
castellano de Becse con otro ${ }^{86}$. La relación que hizo el maestre de campo sobre los deberes en estos dos castillos ya era tardía, pues dos-tres semanas después, el 19 de septiembre cayó Becse y el 25 Becskerek en poder de los turcos. Los dos castillos en estos planes de Aldana fueron considerados de suma importancia, pues fueron los escudos de Transilvania y cortaban los pasos en el Danubio y el camino entre las fortalezas más importantes de los turcos, Belgrado (Serbia) y Titel (Serbia). Incluso amenazaban los presidios de los turcos en el rio Tisza. El segundo eje de defensa de plan español fue Temesvár. Entre los dos ejes se pensaba poner en el triángulo formado por los rios Béga y Tisza un ejército formado de los defensores de Temesvár, junto con los 300 españoles, racianos y villanos convocados por el capitán general András (Andrés) Báthory. Este ejército hubiera contado unos 1000-1200 soldados regulares y otros pocos miles de irregurales racianos y villanos. La estrategia radicaba en obstaculizar con fuerzas pequeñas el paso del enorme ejército turco por el río Tisza, pues los invasores disponían de pocos barcos y nazadas. Es evidente que con unas fuerzas tan pequeñas casi de 1000 (Aldana no podía contar con la lealtad de los racianos, ni que los convocados de las comarcas se reunieran.) hubiera sido un suicidio salir al campo contra el ejército de belerbey, que superaba los 50.000 soldados. Este plan irreal fue presentado a los capitanes de la región, como Losonczy y Báthory. Ellos, con la gran experiencia que tenían en las luchas contra los turcos lo rechazaban. Pero el orgullo del maestre de campo fue profundamente ofendido. Es incomprensible porqué consideraba Aldana a los castillos Becse y Becskerek como ejes de defensa, en conciencia de que los turcos estaban en punto de cruzar el Danubio vía Becse. Además los muros y bastiones de estos dos castillos fueron absolutamente inutiles, débiles, anticuados contra un ejército fuerte, como el de los turcos ${ }^{87}$.

Según mi consideración, podría ser que el autor anónimo del diario omitó intencionadamente esta parte. Le podría parecer también irreal el plan presentado por Aldana. Además, la descripción del mal análisis de la situación hubiera podido contradecir a la imagen de buen estratega, pruedente y valiente capitán, que tenía como objeto el diario. No podemos excluir la posibilidad que

vendria al servicio de Vuestra Majestad y a la Cbristiandad si el viene en manos de turcos y que no sabe remedio como se repone esta tierra y de Xodad [Csanád, Hungria] aknque la tierra está flaca mas flaco esta Sigismundo.x

${ }^{86}$ Los castellanos de Becse en septiembre de 1551: Gábor (Gabriel) Fügedi, Tamás (Tomás) Szentannnai. Compárase: RónAi HoRvátH (1896) 50; CZímer (1893) 31. SZÁDeCZKY LAJOS: Magyar levelek a XVI. század közepébôl. In: Történelmi Tár, 1880, 597-601. Szádeczky en vez de Szentannai menciona János (Juan) Szentimrey. Si las dos personas no son las mismas, entonces estos dos fueron cambiados por Aldana. Véase HHStA Hungarica, fasc. 59, fol. 20, Extractos de las cartas de Aldana, escritas en septiembre de 1551:

"Que ba escrito La neceridad que tenian las fortalezas de Beche y Bechquereque de municiones y les ba enbiado de las que alli avia y dado aviso a Bathori para que quando vuelve procure de llevar consigo algunas.

Ha quitado el capitan de Beche y puesto otro mas conveniente.

8t Véase: nota 84 . 
Aldana estaba pensando adelante, en la posible fortificación, cuando los castillos de Becse y Becskerek fueran reconquistados. En la correspondencia no se encuentra ninguna huella de ello, incluso le contradice el plan paralelo con los ejércitos en campo.

En cuanto el primer asedio de Temesvár, entre el 17 de octubre y el 27 de octubre de $1551^{88}$, la correspondencia matiza nuestros conocimientos hasta ahora. Aquí yo he hallado sólo una cosa digna de mencionar: la ambición y celos de Aldana contra Losonczy que translucen los papeles. El maestre de campo no sólo mencionaba siendo vicecapitán con competencias especiales del húngaro, que Losonczy le había obedecido, como si el propio general supremo, Castaldo hubieta estado allí, sino que al final de la carta pretendía intrigar contra Losonczy, que aunque era un caballero valiente, no estaba dispuesto a servir al rey en un castillo encerrado sino quería seguir como capitán de caballería. Para conseguir el alejamiento de Losonczy del cargo del capitán de Temesvár, el español comenzaba su campaña de intriga, que acabó con la intervención y mandamiento del príncipe Maximiliano, que obligaba a los dos a dejar de riñar y procurar a proteger la comarca encargada a ellos.

«...Estefano de Losonze es muy valiente cavallero y asi lo ba mostrado con la lanf̧a en la mano siempre que aquí se a ofressido con los turcos por en esto de esperar artilleria y exercitos y defender la tierra. Hallase un poco enbarasçado ya le escandalizado lo presente de manera que teme mucho lo futuro y el me a dicho que por ninguna via esperara aquí otra grita. Bien veo que enbiará a pedir licencia a Vuestra Majestad con algunas causas que el pretende... 89

Surge la pregunta: cla correspondencia confirma o no las afirmaciones del diario? Es evidente que el valor documentario del diario no disminuye, sólo por el hecho que omite o transcribe partes que presenten de forma muy negativa a la figura de su héroe. El prefacio crítico hecho por Szakály nos aclara estas exageraciones y modificaciones. Las cartas en general relatan de misma manera los acontecimientos, como el diario, incluso en muchas partes ayudan a fijar bien la cronología exacta del manuscrito. La crítica de la cronología del diario, hecha por Szakály en las notas al final del tomo nos revela la enorme precisión de Aldana. Los acontecimientos de verdad sucedían en aquel día, como figuran en el libro o en la correspondencia. Las cartas nos facilitan la puntualización extra de la expedición contra los castillos del norte de Hungría en 1549.

¿Quién es el escritor anónimo del diario? Las cartas de Aldana fueron despachadas al rey Fernando. Las podía utilizar sólo un escritor que estuviera en la corte, en contacto cotidiano con el rey y que tenía permiso y acceso a la correspondencia real. Tenemos que buscarle entre las personas más cercanas al rey,

RODRIGUeZ VILLA (1878) 80-86. El segundo asedio es entre 24 de junio de 1552 hassa 27 de julio. Los defensores, junto con Losonczy y los soldados de las banderas españolas de los capiranes Gaspar de Castelvi y Rodrgio Villadrando fueron matados.

89 HHStA Hungarica, fasc. 60, fol. 84-85, Bernardo de Aldana a Fernando I, 28 de octubre de 1551. Véase también SzAKÁLY (1986). 
consejeros, secretarios, etc. Szakály analizaba la opinión de la historiografía española y afirmó que de ninguna manera había podido ser el autor el hermano de Bernardo, fray Juan Villela de Aldana, como había supuesto Rodriguez Vi1la ${ }^{90}$. Tampoco Pedro Barrantes Maldonado, su tío, posesor de muchas cartas escritas por Aldana, pues no pasaba por Hungría y el autor conocía bien no sólo el país, sino - - lo que es más dificil- transcribía correctamente los nombres y los topónimos. En 1556 don Luis Venegas de Figueroa y don Pedro Lazo de Castillo intervenían en nombre de Felipe II, por la libertad de Aldana encarcelado. Ellos hubieran podido tener acceso a la correspondencia, pero es poco probable que estos dos aristócratas escribieran una apología por un humilde maestre de campo. Yo incorporaría entre los posibles autores al secretario de Fernando, Juan de Castillejo ${ }^{91}$, hasta el momento el único que cumplía todos los requisitos: conocía el país, tenía acceso a las cartas del rey, incluidas las escritas por Aldana, podría estar sentado junto a él en la audiencia de Juan Villela de Aldana, estaba en contacto personal con el maestre de campo, obteniendo así informaciones adicionales: El era aquel secretario a quien Aldana le encargó a solucionar los problemas de la tenencia de Sedella. O sea, estaba en un contacto de cierta confianza porque es poco probable que el ambicioso Aldana encargara a una persona cuestiones de tanta importancia para él, con quien no tuviera una relación más o menos estrecha ${ }^{92}$. Junto a Castillejo había otros españoles en la corte de Viena que podrían cumplir los requisitos de ser autor. Pero de nombre -y mencionado por Aldana - sólo conocemos a él. La problemática queda así también sin solución, pues no disponemos de pruebas directas.

¿Podían servir las cartas, como fuentes? Si, pero sólo en el caso de si el autor utilizaba otras cartas más detalladas o personalmente participaba en los acontecimientos, porque en algunos episodios el diario es más detallado que la correspondencia (por ejemplo la expedición de 1549), en otros es menos (como la fortificación de Szolnok, la expedición turca de 1551). Ha de pensarse, que el diario cuenta más sobre aquella expedición, donde los soldados varias veces se amotinaban y fue despachada una comisión para investigar las circunstan-

90 Véase RODRIGUEZ VILLA (1878) 24, SZAKáLY (1986) 13-16, en la p. 257 el autor relata en primera persona, que en la audiencia real sobre el caso de Aldana su hermano, Juan presentaba en pie su relación, mientras él estaba sentado (!) junto al rey, frente a Juan (!) y oía todo, sin haber perdido una palabra. RODRIGUEz VIILA (1878) 106, lo cita en forma abreviada.

91 Sobre Castillejo véase supra. En la correspondencia de Martín de Salinas encontramos muchas referencias a la actividad del secretario. In: Rodriguez VILIA, A.: El emperador Carlos $V$ y sa corte según las cartas de Martín de Salinas. Madrid, 1903.

92 HHStA, Hungarica, fasc. 55 fol. 13-14, Bernardo de Aldana a Fernando I, 3 de mayo de 1549, Léva. Además de esta Addana le envió la relación de la muestra hecha en Szolnok y le encargó, que hiciera relación al rey sobre la fortificación del castillo: HHStA, Hungarica, fasc.56, fol. 42. Bernardo de Aldana a Fernando 1, I de septiembre de 1550, Komárom. 
cias $^{93}$. O sea, había una correspondencia más minuciosa. Siguiendo la hipótesis de arriba, el autor - sea Castillejo o no- habría podido ser el miembro de la comisión o/y teniendo acceso a las relaciones en su diatio podría aprovechar la información adicional, obtenida de los comisarios. Hasta que dispongamos de fuentes de control me atrevo de plantear esta idea insegura. Disponemos de dos cartas de dos personajes quienes no formaban parte de la expedición, pero hacia los finales de julio presentaron dos relaciones al rey Fernando sobre el resultado de sus negociaciones con el conde de Salm, con Aldana y con otros capitanes y soldados. En las relaciones detalladamente analizaban las causas de los motines, las tensiones entre los capitanes y jefes de la expedición. Los dos enviados son personajes bien conocidos de la corte de Fernando: Bernardino de Meneses y Alonso Mercado ${ }^{94}$.

La mala fortuna de Aldana en Hungría produjo en la historiografía húngara una imágen llena de errores y prejuicios. Se le consideraba mercenario alemán, se acusaba de que el dinero recibido para la fortificación de Lippa, lo había robado9s. La historiografía húngara del siglo pasado le consideraba cobarde, versatil, vil ${ }^{96}$. Desafortunadamente la historiografía actual tampoco ha cambiado su postura97. Es evidente que estos estereotipios han derivado de la opinión del máximo enemigo, Giovanni Baptista Castaldo, quien argumentaba y luchaba por la condena de Aldana, no sólo por sus antiguas confrontaciones personales, sino también para ocultar, o hacer olvidar el fracaso de su política intolerante e inpensada en Transilvania, y su papel en el asesinato del cardenal

93 Las cartas dedicadas a los miembros de la comisión: HHStA Hungarica, fasc. 55, fol. 60-63, s.l. s.f.

91 HHStA Hungarica, fasc. 55, fol. 39-40, 40-44. Bernardino Meneses y Alonso Mercado a Fernando, 24 y 28 de julio de 1549, Viena. En estas cartas Meneses hace referencias a su estado de salud y a su mayor edad, llamando la atención del rey, que ume ven viejo y que paso cuarenta años de servicio [de Vuestra Majestad]...». Sobre la actividad diplomática y política de Meneses y Mercado desde los comienzos de los 20 véase: RODRIgUez viLA (1903), passim, Miguel ANGEL OCHOA BRUN: La diplomacia de Carlos V. Madrid, 1999. Historia De la Diplomacia esPañola. Vol. 5. Biblioteca Diplomática Española. Sección estudios 6,117-120 y passim.

${ }^{95}$ RóNAi HORVÁtH (1896) 49, 56. Szakály aclaraba que Aldana no habia defraudado el dinero. Incluso para la fortificación de Temesvár y Lippa en 1552 Aldana y Losonczy no disponían más de 5.000 o 7.500 de oro. Véase Szakály (1986), 20.

9 RÓNAI HORVÁTH (1896) 61; KROPF (1895-96) passim; CZímer (1893) passim.Es característica la opinión de SánDOR KaTó: Idegen katonatág Magyarországon I. Ferdinánd uralkodása datt 1540-1564. Gyór, 1908, obra llena de errores y prejuicios. Aldana aparece como capitán de la caballería, en vez de la infantería. Encontramos los mismos estereotipios, como malversador, vil, etc. La competición entre Losonczy y Aldana está presentada unilateralmente, o sea Aldana, odiando al capitán húngato eta capaz hacer todo para que lo viera muerto y por esta razón no apoyo al castillo de Temesvár encabezado por Losonczy y dejó morir a los defensores, entre ellos dos banderas españolas suyas. Y luego, al haber recibido la noticia sobre la muerte de su rival y sobre el paso de los turcos hacia Lippa, abandonó al castillo encargado.

${ }_{97}$ GÉZA PÁl.FFY: Várfeladók feletti ítélkezés a 16-17 századi Magyarországon. (A magyar rendek hadügyi jogkörének kérdésêhez). In: Levéltári Közlemények, 1997. 1-2, 216; SzÁNTó (1985) 136. 
Jorge Martinuzzi. Como la correspondencia de Castaldo era y es una de las fuentes más frecuentemente usadas para la historia de estos años, influía en la imagen actual de Aldana ${ }^{98}$. La publicación del diario en cuidado de László Scholz (trad.) y Ferenc Szakály matiza, incluso se opone a la opinión negativa, tan divulgada. Esta correspondencia presentada en este artículo completa la obra y opinión de los dos.

Un error curiosísimo aparece en la fuente utilitísima de Istvánffy, publicada en 1622. Según él el tercio español fue encabezado por Pedro Zapata y Gaspar Castelnovo 99 . En esta forma las dos figuras no existen en el diario. Sin embargo en el diario aparece varias veces - sobre todo en el asedio segundo de Temesvár, en 1552 - el capitán Gaspar de Castelvi de origen sardo, quien supuestamente la misma persona que la de Istvánffy. Mientras tanto Pedro Zapata - junto con Wolfgang Pratner- habían pasado por Hungría durante el año 1532, cuando los dos por el encargo de Carlos I reclutaban, como comisarios imperiales, caballería ligera húngara (huzares), muy apta contra los turcos ${ }^{100}$. Ni en el diario, ni en la correspondencia aparece su nombre.

En el diario en húngaro no queda claro el número de soldados del tercio español. El autor consecuentamente menciona seis banderas y 1200 soldados. Las cartas publicadas al final del diario dedicadas al tío Maldonado mencionan 7 banderas y 1400 soldados ${ }^{101}$. La correspondencia de igual modo. Según estas fuentes podemos reconstruir los siete capitanes del tercio: Diego Vélez de Mendoza, Luis Vélez de Mendoza (durante de 1551 Mendoza se fue a Nápoles, el capitán de su compañia sería Francisco de Aldana, primo de Bernardo) ${ }^{102}$, Gaspar de Mardones (a mediados de mayo de 1549 Mardones había vuelto al servicio de César. Su lugar ocupaba Juan de Ulloa, hermano del fallecido capitán Gonzalo de Ulloa) ${ }^{103}$, Luis de Barrientos, Luis de Ordoñez (fallecido en 1551, después de su

\footnotetext{
98 La correspondencia de Castaldo en latín y otras fuentes: SAMU BARABÁs: Erdély történetéte vonatkozó regeszták. 1551-1553. In: Történelmi Tár, 1891, 1892. 1-6 publicaciones; SZÁDECZKY (1880) 597-601; ANDRás KomáromY: Magyar levelek a XVI. század közepébôl. In: Tơrténelmi Tár, 1907,1908, 1911. 1-8 publicaciones.

99 ISTVÁNFFY (1871) 326.

100 Instrucciones de Carlos I a sus embajadores en Pozsony (Bratislava, Eslovaquía), Zapata y Pratner. 11 de junio de 1532. Academia de Ciencias de Hungría (MTA), Copias de documentos del Archivo de Simancas. MTA Ktt. MS. 4939 leg 636 fol. 235/236. El encargo de los dos comisarios fracasó a causa de la falta de paga y por la desconfianza de los estamentos húngaros, que el ejército imperial se aprovechara de la conquista de Hungría a favor de Fernando, en vez de la expulsión de los turcos. Véase también la carta de Pedro Zapata al Condestable de León 16 de junio de 1532. MTA Ktt. MS. 4939 leg 635 fol. 139, 140.

101 SZAKÁly (1986) 262.Bernardo Villela de Aldana a Pedro Barrantes Maldonado, 1549.

102 Este Francisco que murió en el asedio de Lippa en 1551, no era el poeta Francisco de Aldana, que murió en la batalla de Alcazarquivir.

${ }^{103}$ SZAKÁly (1986) 61. En el prefacio de la obra se menciona Gonzalo, quien en 1548 en Reutlingen fue despedido, cuando Aldana reformaba su tercio. Compárase carta 3, fol .9.
} 
muerte el capitán sería Gaspar de Castelvi.), Pedro de Avila ${ }^{I 04}$ y el séptimo era el maestre de campo, Bernardo de Aldana.

Este tercio de 1400 soldados durante la expedición de 1549 tendría enormes pérdidas. Si sumamos los héridos y fallecidos según diario y la correspondencia, nos salen 93-102 muertos, 190-300 heridos ${ }^{105}$. Pero la relación del contador Diego de Aguirre después de Murány nos comunica un dato chocante: de cada compañia faltan 50 soldados, en total casi con 450 , o sea con $1 / 3$ parte contaba menos en agosto de 1549 , como había tenido en Rajka, al entrar en Hungría los finales de $1548^{106}$. La explicación es que al lado de las pérdidas en combate, desde los mediados de mayo, cuando los precios se habían aumentado más y los soldados desertaban. El númeto de 1400 se completaría sólo durante el invierno de 1549/50, cuando el ejército se trasladó a Pápa (Hungría) ${ }^{107}$.

Bernardo de Aldana y su tercio español entre 1549 y 1552 desempeñaban un papel sumamente importante en las guerras dirigidas por el gobierno militar de Fernando I en Hungría. Aunque la mayoría de los mercenarios que luchaban en Europa Central Oriental no dejaron un recuerdo positivo en la memoria histórica magyar, podemos subrayar el hecho de que -como muestra la suerte de Aldana - este reino, debilitado por su propia fuerza, nunca hubiera podido salvarse del poder turco sin el apoyo de los hermanos Habsburgo. Estos españoles, protagonistas de estas páginas pueden simbolizar la otra cara de la moneda; aunque bien es cierto que la ayuda prestada por Carlos I a su hermano contra los turcos siempre estaba por debajo de las pretensiones requeridas tanto por el rey, como por sus vasallos húngaros. En general, se puede decir que su papel fundamental fue el de frenar la expansión turca en Hungría, sin la esperanza de expulsarlos; objetivo que se presentaba demasiado ambicioso en

${ }^{104}$ HHStA Hungarica, fasc. 55, fol. 60-61, Bernardo de Aldana a unos señores desconocidos.

105 Szitnya (Sitno Eslovaquía): muertos 7 infantes y 1 artillero, heridos 25; Léva (Levice, Eslovaquía): muertos 27 , heridos 60 . (fasc. 55 , fol. 21-22, 16 de mayo de 1549: muertos $22-23$ y heridos 70); Csábrág (Čabradsky Vhovok, Eslovaquía): muertos 5 y heridos 2 (Según el diario el casti1lo fue tomado sin sangre.); Revueltos después de Csábrág: muertos 2 heridos 5 (Sin contar los 1415 pajes de nacionalidad desconocida, muertos de los españoles); Murány (Muran, Eslovaquía): muertos 60 y heridos 200. (fasc. 55, fol. 52-54, 16 de agosto de 1549: muertos 50 y heridos más de 100.) Las diferencias entre las dos fuentes radican en que una sería más tardia, comparándola con la otra, cuando algunos heridos graves también habrian podido fallecer.

${ }^{106}$ HHStA Hungarica fasc. 55, fol. 59, el contador Diego de Aguirre a Fernando I, 1549. Murány.

to7 Sobre el papel estrarégico de Pápa véase: GÉZA PÁLFY: Pápa szerepe a XVI. századi végvárrendszerben. In: Tanulmányok Pápa város történetéból. Pápa, 1996, tomo 2. 81-98. Ferenc SZAKálY: Pápa a török korban. In: Tanulmányok Pápa váres történetébôl kezdetekt ô 1970-ig. Pápa, 1994, tomo 1. $125-200$.

Hispania, LX/3, núm. 206 (2000) 881-910 
aquellos momentos. El sueño primordial del César se deshacía en el frente más importante de las luchas antiturcas de Europa del siglo XVI, debido a que las luchas dinásticas de Europa Occidental se imponían a las primeras.

Tanto en la historiografia húngara como en la española se requiere un análisis sistemático de las luchas antiturcas, porque el emperador en sus guerras contra el enemigo de la Fe no pensaba sólo en un frente español y en otro húngaro, sino que en realidad tenía una visión global, supranacional. Desafortunadamente, las historiografias nacionales no tienden a salir fuera de sus propios marcos, que es una posición dificilmente defendible en el caso de una figura tan europea, como era Carlos V. Se necesitará también demostrar en el conjunto de las guerras contra el bostis naturalis en este periodo los motivos comunes que en el fondo enlazaban y movían la política de las dos regiones, con respeto al turco. Aunque estas motivaciones muchas veces - como en el caso de Aldana también- le obligaban a España y sobre todo a Castilla a asumir cargas gravosas que estaban en contradicción con sus intereses nacionales.

Por lo que se refiere a Aldana, es claro, después de todo lo dicho, que el diario y la correspondencia mutuamente se complementan el uno al otro como fuentes históricas básicas, que nos proporcionan una visión mucho más matizada y real de los hechos del tercio español y de la política de los habsburgo en Hungría entre 1549 y 1552 de la que se venía teniendo hasta ahora. La ulterior profundización en estos matices permitiría, según mi opinión, esquivar la mayoría de los prejuicios que la historiografia romántica de Hungría había declarado con respeto a las actividades de los «Tercios Viejos» en Europa Central Oriental. 